\title{
Application Analysis of Vector Model and GIS System Data in the Substation Engineering Entire Life-cycle
}

\author{
Kaihang Sun ${ }^{1, *}$, Xinze An ${ }^{1}$, and Shunkai Feng ${ }^{1}$ \\ ${ }^{1}$ POWERCHINA HEBEI ELECTRIC POWER ENGINEERING CO.LTD., Shijiazhuang, Hebei, China
}

\begin{abstract}
With the further popularization of 3D design in substation engineering, the previous works provide lots of data foundations for digital operation and maintenance. Different from the editing requirements of the model in the design stage, higher requirements are put forward for the corresponding speed of the model and the bearing capacity of the graphics platform in the operation and maintenance stage. At present, the application methods of model library are mainly based on geographic information data (GIS) and vector graphics platform. In this paper, the model data are analysed and compared from the dimensions of analytic speed, graphic effect, operation efficiency, integrity and storage space, etc. The graph platform based on geographic information data can better support the application of the model in operation and maintenance stage.
\end{abstract}

\section{Introduction}

From 2017 to now, State Grid Corporation of China and China Southern Power Grid Corporation of China have formulated a series of data standards for 3D design of substation projects, which strongly promote the progress and development of 3D design. At the same time, the design unit can effectively improve the design quality and efficiency of substation and realize the visualization of design and the digitization of engineering information through the digital design of substation engineering. With the end of the design, a large number of 3D design data of substation engineering have been accumulated. When the model data is handed over to the owner, the data information can run through the design, construction, operation, maintenance and decommissioning, and the multi-stage, multi-link and multi-department joint maintenance and use can support the operation and management of the whole life cycle of the substation ([1]).

Demands are come from the design, construction, owner, software companies are have developed platforms based on geographic information data (GIS) and vector graphics platform. Such as Guoyao Co.LTD.'s EV-Globe and SuperMap Co.LTD.'s 3DGIS, these are all based on geographic information data, at the same time combine with 3D graphics, engineered structured and unstructured data. However, Autodesk 's Naviswork and Bentley 's Navigator are based on vector graphics platform. These companies aim at improving the lightweight loading, display, application of models. These two technical routes must have an impact on the application of the whole life cycle of three-dimensional design. Therefore, it is necessary to analyze and compare the model data analysis speed, graphic effect, operation efficiency, integrity and storage space, and select a platform that can meet the digital application of power grid engineering.

\section{Application analysis of vector graphics platform}

The most widely used 3D design software in the field of substation is the series of software developed by STD-R and Bentley based on Microstation ([2]). These two 3D design software are supported by 3D model and database, realizing the association between model and data, and meeting the requirements of multi-specialty collaborative design in substation engineering.

The data and storage structure of * RVT generated by STD-R and *. DGN model generated by Bentley are quite different, Naviswork and Navigator, a vector graphics platform developed on the $\mathrm{C} / \mathrm{S}$ end, can effectively integrate multi-format model data, and then share and review detailed 3D design models, so as to optimize design, implement project management and operation.

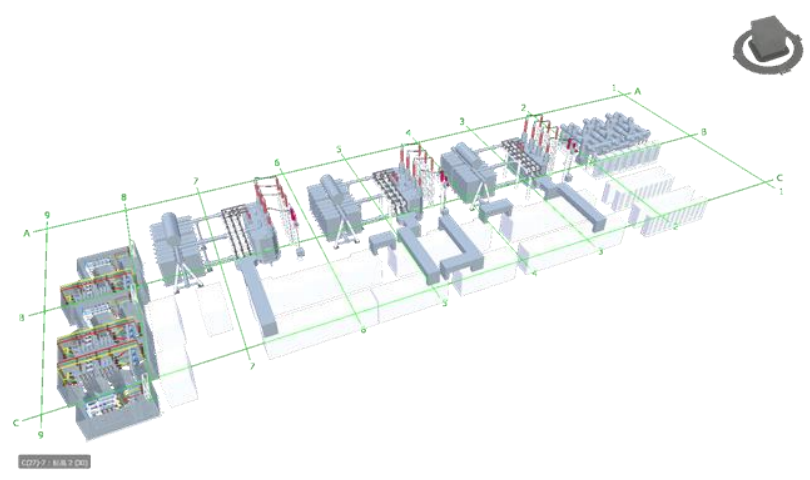

Fig. 1. Lightweight treatment of electrical equipment model.

Corresponding author: sunsyzjf@qq.com 
The vector graphics platform can check the collision of transformer model data, find out the collision elements, and feedback the adjustment in the design software so as to complete the optimization design.

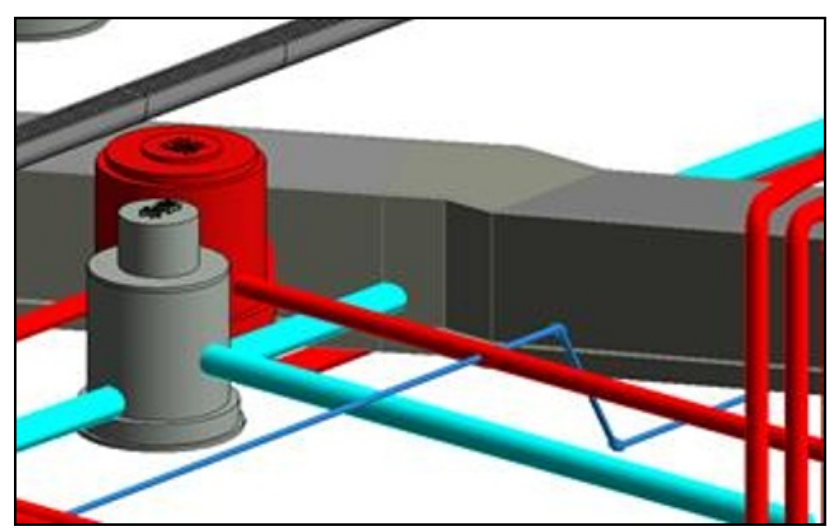

Fig. 2. Collision inspection in substation project.

The time axis is added to the vector graphics platform, which can simulate the construction by setting the time of drawing elements, improve the construction process management, and ensure the time limit of the substation project.
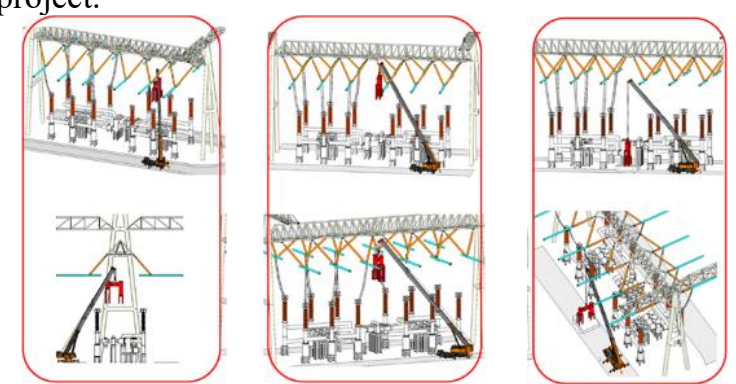

Step01: Lifting

\begin{tabular}{|c|c|c|}
\hline 5 & $\begin{array}{c}\text { Operational } \\
\text { stage }\end{array}$ \\
\hline 6 & $\begin{array}{c}\text { Data } \\
\text { management }\end{array}$ \\
\hline
\end{tabular}

Real-time display, dynamic

simulation, operation and

maintenance maintenance of substation operation data

Realize the management of

models, data, documents, information

\section{Application and analysis of geographic information data graphics platform}

In recent years, with the application and research of 3D design technology, software companies such as Guyao EV-Globe and SuperMap have studied and established design information integration technology based on equipment model (including 3D graphics, geographic information, engineering structured and unstructured data) ([4]), promoting the application of the whole life cycle of 3D design, making the design results gradually transition from engineering design drawings to $3 \mathrm{D}$ design results.

At present, state Grid corporation of China and China Southern Power Grid Corporation of China have formulated a unified and open interactive standard and format for 3D design model of substation (Grid Information Model, GIM), realizing the import and output of geographic information data graphics platform. Model data can still be editable after the interaction of different design software and functional platforms, which runs through the whole process of power transmission and transformation engineering. The application data flow of power grid GIM model is shown in Fig.3.

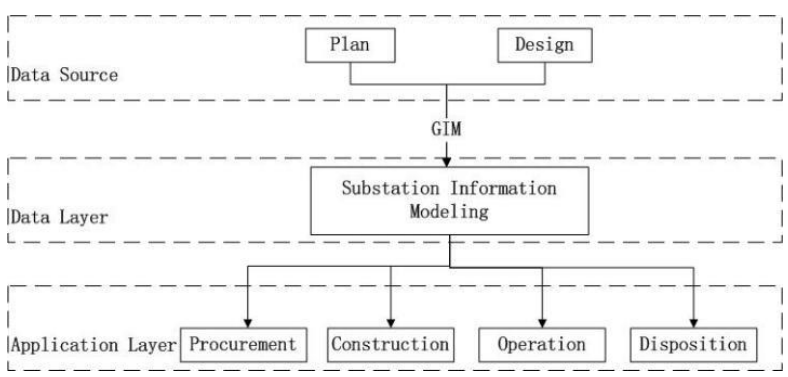

Fig. 4. The data flow of GIM model application.

After importing THE GIM data into the graphic platform of geographic information data, the platform provides general graphic functions such as attribute query statistics, visibility analysis, net distance measurement, roaming, cutting for the engineering model, and can realize the analog and visual construction of the engineering.

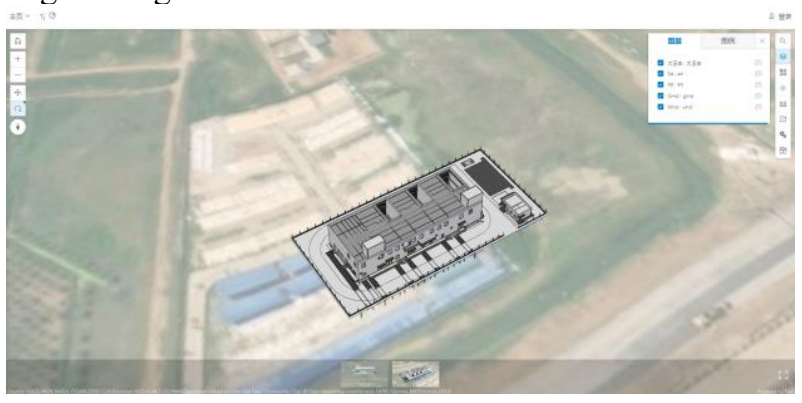

Fig.5 Application of geographic information data graphics 
The geographic information data graphics platform can realize multi-data integration and expansion: the basic geographic data is mainly used to restore the terrain and geomorphology of the site; The 3D grid model restores the real scene of the circuit and substation; The two work together to build a three-dimensional distribution scene of grid space([5]).For example, in the operation and maintenance stage ,the methods of fault location analysis and power flow analysis can be used to quickly carry out tripping, reversing and other remote operation in case of substation failureFor example, in the operation and maintenance stage, the methods of fault location analysis and power flow analysis can be used to quickly carry out tripping, reversing and other remote operation in case of substation failure. The methods can analyze the area of influence, and provide decision support for power grid dispatching and operation.

Table.2 Application and analysis of geographic information data graphics platform

\begin{tabular}{|c|c|c|}
\hline $\begin{array}{c}\text { Serial } \\
\text { number }\end{array}$ & Function & Describe \\
\hline 1 & $\begin{array}{l}\text { Detection } \\
\text { and audit }\end{array}$ & $\begin{array}{l}\text { Soft and hard collision } \\
\text { inspection, review and } \\
\text { verification;Meet the internal } \\
\text { collaborative design }\end{array}$ \\
\hline 2 & $\begin{array}{l}\text { Construction } \\
\text { simulation }\end{array}$ & $\begin{array}{l}\text { The combination of time and } \\
\text { schedule is applied to the } \\
\text { construction stage }\end{array}$ \\
\hline 3 & $\begin{array}{c}\text { Roaming } \\
\text { animation }\end{array}$ & $\begin{array}{l}\text { Achieve man-machine } \\
\text { interaction, roaming review }\end{array}$ \\
\hline 4 & $\begin{array}{c}\text { Strong } \\
\text { compatibility }\end{array}$ & $\begin{array}{l}\text { Integration of different software } \\
\text { models }\end{array}$ \\
\hline 5 & $\begin{array}{l}\text { Operational } \\
\text { stage }\end{array}$ & $\begin{array}{l}\text { Real-time display, dynamic } \\
\text { simulation, operation and } \\
\text { maintenance maintenance of } \\
\text { substation operation data }\end{array}$ \\
\hline 6 & $\begin{array}{l}\text { Geographic } \\
\text { information } \\
\text { data } \\
\text { utilization }\end{array}$ & $\begin{array}{l}\text { The space grid is perfectly } \\
\text { combined with the substation, } \\
\text { giving play to GIS location } \\
\text { service and spatial analysis }\end{array}$ \\
\hline 7 & $\begin{array}{l}\text { Sensory } \\
\text { fusion of } \\
\text { things }\end{array}$ & $\begin{array}{l}\text { Integration of intelligent } \\
\text { hardware implementation, } \\
\text { perception of substation dynamic } \\
\text { information, operation, } \\
\text { management }\end{array}$ \\
\hline 8 & $\begin{array}{c}\text { Oblique } \\
\text { photography }\end{array}$ & $\begin{array}{l}\text { Tilt photography and model are } \\
\text { placed under the same reference, } \\
\text { forming an integrated real } \\
\text { geographical space scene from } \\
\text { outdoor to indoor, from macro to } \\
\text { micro }\end{array}$ \\
\hline
\end{tabular}

\section{Comparative analysis of platform graphics performance}

The vector graphics platform represents the similar geometric shapes through triangulation technology, and improves the optimal graphics performance by means of blocking removal, batch rendering and multiple LOD. Under the condition that the device model does not lose truth, the GEOGRAPHIC information data platform can simplify a variety of fine grid device models and construct multi-detail level model files. At the same time, a blockindex mechanism was established for model geographic files to improve the speed of model searching and reduce the real-time load of the model, thus realizing the dynamic dispatching of the three-dimensional model of the power grid.

In this paper, a $500 \mathrm{kV}$ substation is selected to conduct comparative tests on the analytic speed, graphic effect, operating efficiency, integrity and storage space of the vector graphics platform and geographic information data platform respectively. The vector graphics platform was chosen Naviswork from Autodesk and the geographic information data platform was chosen EV-Globe from GuoYao. The $500 \mathrm{kV}$ substation adopts Bochao STD-R for 3D design modelling. The model and data information all meet the requirements of State Grid handover standard. the model file is $1039.5 \mathrm{MB}$ in total.

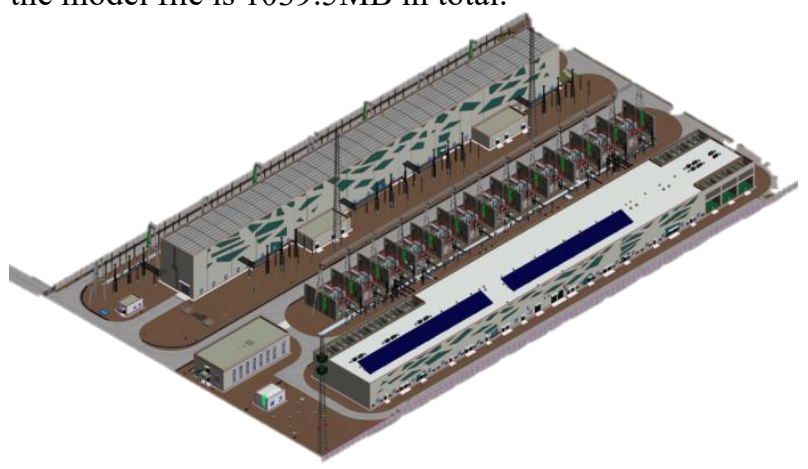

Fig.6 The effect of substation

\subsection{Parsing speed}

The substation model is imported into Naviswork platform in RVT data format and EV-Globe platform in GIM data format. The results showed that Naviswork was faster than EV-Globe. The former went through two intermediate processes, a geometry transform and a rendering process transform, while the latter required an additional data transform, which increased the time by about $30 \%$. As a result, in the model analysis link Naviswork the platform dominates.

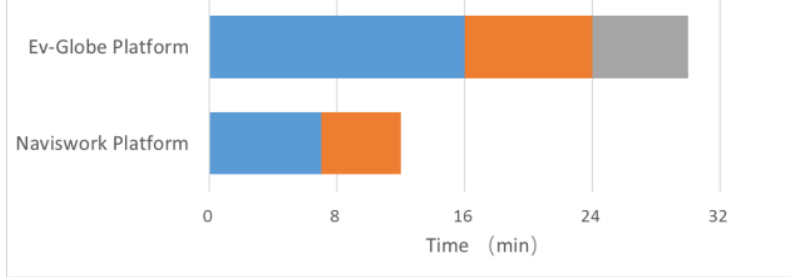

Fig.7 The speed of model resolution

\subsection{Graphic effect}

Both of the two graphics platforms can render the images of the transformer 3D model, colour the graphics and give the materials. The effect can meet the application requirements of the whole life cycle of the substation.

And the two platforms also support a variety of display effects, such as flame, water surface, thermal diagram and 
so on, to meet the later model application simulation requirements.

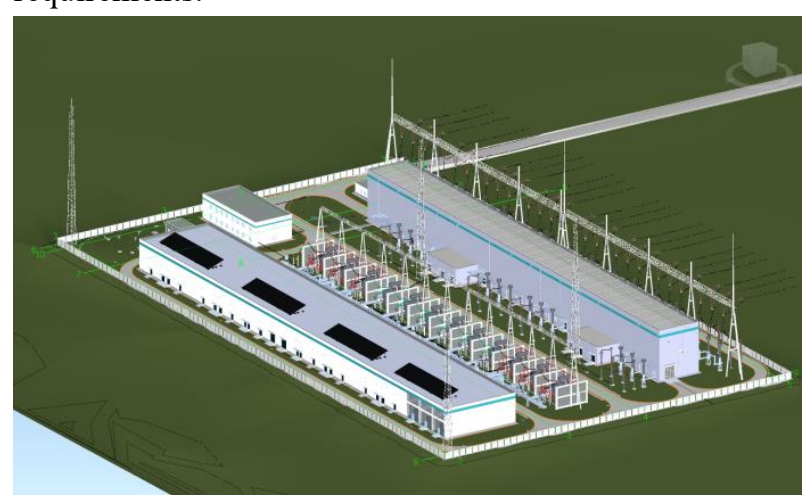

Fig.8 The effect of Naviswork platform graphic

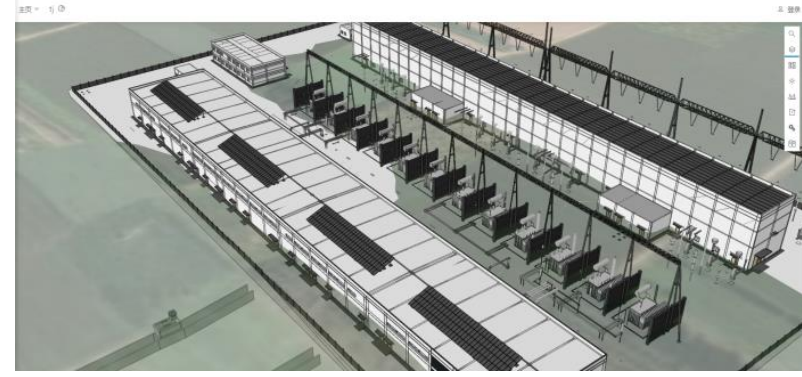

Fig.9 The effect of Ev-Globe platform graphic

\subsection{Run load efficiency}

The partitioning index and tile loading technology of geographic information graphics platform make the loading of EV-Globe platform model $15 \%$ faster than that of Naviswork platform. It can match the display effect of the model according to different scenes, and the operation efficiency is significantly improved.

Ev-Globe Platform

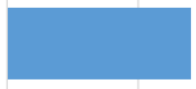

Naviswork Platform

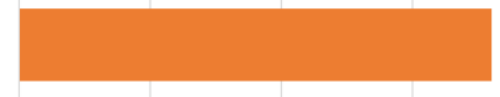

0

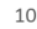

Time ( $)$

Fig.10 Model operating efficiency

\subsection{Integrity}

After analyzing the data of the design model, both of the two graphics platforms can completely retain the physical and attribute information of the model. And both platforms can be associated with SQL 、 MySQL 、 MongoDB and other databases, which can extend the attribute information of construction, operation and maintenance, equipment monitoring and support the application data requirements of the whole life cycle.

\subsection{The storage space}

After the analysis of two graphics platforms, the data compression ratio of Naviswork platform reached 10.2, and that of EV-Globe platform was 9.5. The Naviswork platform requires less storage space. The reduced storage space has little effect on the model data storage.

Ev-Globe Platform

Naviswork Platform

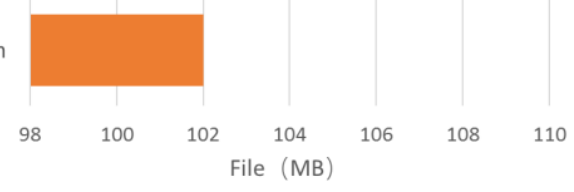

Fig.11 Model Integrity

\section{Conclusion}

With the development of 3D design technology, a large amount of model data needs to be carried by a graphics platform. The geographic information data graphics platform can adapt to the grid structure and intensive distribution structure. The geographic information data graphics platform is connected with other business and analysis systems, realizing the integrated application of data analysis, real-time monitoring, operation and maintenance management and fault diagnosis and meeting the requirements of full life cycle engineering. Geographic information data platform is superior to vector graphics platform in terms of parsing speed and loading efficiency. The required storage space is $8 \%$ larger than that of the vector graphics platform, while there is no significant difference in other indicators.

However, the geographic information data graphics platform presents the real geographical environment through the integration and expansion of multiple data, topography and geomorphology, and restores the real scene of the power grid engineering lines and substations, and the connection between the belt transmission lines and the point-shaped substations, and jointly builds the three-dimensional distribution scene. Therefore, it can better support the application of the model in operation, maintenance and other links, and has more extensive application value.

\section{References}

1. Sihang Li, Jianlong Sun, Hongwei Zhou, Yuqiang Zhou, Bing Zhou, Electrical Engineering, v.19, 103(2018).

2. Dakai Sheng, Xin Zou, Junhui Hu, Zhili Wu, Lizhong Qi, Electric Power Construction, v.34, 1(2013).

3. Zhili Wu, Wenju Han, Electric Power Construction, v.35, 66(2014).

4. Yijun Fang, Xiongwen Wang, Song Liu, Gaiping Shi, Electric Age, No.450, 57(2019).

5. Peixiang Ren, Xiaobo Hou, Yan Guo, Jian Dong, Electric Power Survey \& Design, No.85, 61(2015). 